\title{
An efficient in vitro-inoculation method for Tomato yellow leaf curl virus
}

\author{
Ayed M Al Abdallat*1,2, Hmoud S Al Debei' ${ }^{1}$ Heba Asmar'1, Samar Misbeh¹, Ayat Quraan and Anders Kvarnheden³
}

\begin{abstract}
Background: Tomato yellow leaf curl virus (TYLCV) is a member of the family Geminiviridae, genus Begomovirus. To test the infectivity of TYLCV in tomato plants, an improved protocol for inoculation of in vitro-cultured tomato plants was developed.

Results: A TYLCV isolate was cloned, sequenced and used to construct a 1.8-mer infectious clone. Three weeks old microshoots of TYLCV-susceptible tomato plants were inoculated with Agrobacterium tumefaciens harboring the infectious clone for the TYLCV isolate. After two weeks, the TYLCV symptoms started to appear on the in vitroinoculated plants and the symptoms became more severe and pronounced eight weeks post-inoculation. The method was used efficiently to uncover the resistance mechanism against TYLCV in Solanum habrochaites accession LA 1777, a wild tomato known for its high resistance to whitefly and TYLCV.

Conclusions: The reported in vitro-inoculation method can be used to screen tomato genotypes for their responses to TYLCV under controlled conditions and it will be a useful tool for better understanding of the TYLCV biology in tomato plants.
\end{abstract}

\section{Background}

Since it was first reported in the Jordan valley [1], the tomato yellow leaf curl disease (TYLCD), caused by the Tomato yellow leaf curl virus (TYLCV) and related viruses, has become a serious problem that affects tomato (Solanum lycopersicum) worldwide. TYLCV is a member of the family Geminiviridae, genus Begomovirus and it is transmitted to tomato by the whitefly Bemisia tabaci in a persistent and circulative manner [2]. The management of the disease in tomato production areas is difficult and expensive and the control measurements are focused mainly on the whitefly control and are based on insecticide treatments and/or the use of physical barriers [3].

One of the best ways to reduce TYLCV damage is to breed plants resistant to both the virus and the vector. Breeding programs for TYLCV-resistant cultivars are based on the transfer of TYLCV resistance genes from wild tomato species into cultivated tomato [4]. Previous studies have revealed the presence of resistance mechanisms against the virus in wild tomato species that are

* Correspondence: a.alabdallat@ju.edu.jo

1 Department of Horticulture and Crop Science, Faculty of Agriculture, University of Jordan, Amman 11942, Jordan

Full list of author information is available at the end of the article controlled by multiple genes [4-6]. For instance, the TYLCV resistance in S. chilense is controlled by a major gene, termed $T y-1$, and at least two other modifier genes [7]. However, the progress in the breeding program has been slow, primarily due to the complexity of TYLCVresistance genetics and the virus-vector-host interactions [5]. The complexity of TYLCV resistance is reflected by the presence of different resistance mechanisms against the virus and the whitefly. In addition, TYLCD may be caused by different strains of TYLCV as well as other begomovirus species, such as Tomato yellow leaf curl Sardinia virus (TYLCSV).

To test the infectivity of TYLCV and to understand mechanisms of TYLCV resistance in plants, several methods for in vivo screening have been developed such as natural field infection, whitefly inoculation in cages, inoculation with the virus using leaf or stem agroinfiltration or biolistic inoculation [8]. In many instances, such methods have proven to be laborious and pose a potential threat to the environment. For instance, several susceptible tomato plants had escaped TYLCV infection using the method of natural field infection even 90 days after transplanting [9], while with whitefly inoculation in cages, it might be difficult to control the inoculum pres- 
sure [10]. In addition, such natural inoculation methods are not efficient for screening wild tomato species due to their non-preference by whiteflies. In addition, vector activity, virus multiplication and symptom development are affected by the prevalent environmental conditions during and after greenhouse or field inoculation. Agroinfiltration of stems or leaves are laborious, difficult and inefficient in some tomato genotypes [11,12]. Using biolistic inoculations, discrepancies in results related to plant species have also been reported [13-15]. Above all, testing for TYLCV resistance in transgenic plants using in vivo inoculation methods is difficult in open environment or non-specialized greenhouse conditions due to strict regulations for genetically modified organisms. Therefore, there is a need to establish controlled inoculation protocols to prevent any unfavorable spread of the viruses to the surrounding environment, especially when testing new viral strains or recombinants.

Two previous reports have described the development of viral inoculation systems suitable for in vitro plants $[16,17]$. With the described systems, it has been possible to inoculate successfully plants grown in vitro using a mechanical approach. In this study, we report the development and use of an efficient in vitro method suitable for TYLCV inoculation of tomato. The principle for the new inoculation method depends on dipping the basal part of the plant in a solution containing agrobacteria with an infectious TYLCV clone. The method was used successfully to inoculate susceptible tomato plants with TYLCV and to test for TYLCV resistance in wild tomato plants.

\section{Methods}

\section{Cloning of a TYLCV genome}

Leaves from a tomato plant showing TYLCD symptoms were collected from greenhouse-grown plants. Total DNA was extracted from the collected leaves using a CTAB method [18]. The overlapping primer method was used for the amplification of a full-length TYLCV DNA genome with the polymerase chain reaction (PCR) as described previously [19]. In this method, two designed primers, TYJU fwd (5'-TAAATACCATGGCCGCGCAGCGGAATACACGACGTTC-3') and TYJU Rev (5'TATAATCCATGGAGACCCATAAGTATTGTCATT-

GAGGGTGA-3'), that overlap a conserved NcoI site (in italics) in the $C 1$ gene of TYLCV were used in combination with the genomic DNA extract prepared from TYLCV-infected tomato leaf tissue in a PCR. The reactions were performed in a $25 \mu \mathrm{L}$ volume containing 100 ng genomic DNA, $2.5 \mu \mathrm{L}$ of dNTPs $(100 \mu \mathrm{M}), 5 \mu \mathrm{L}$ of $5 \times$ PCR, $0.5 \mu \mathrm{M}$ of each primer and $0.25 \mu \mathrm{L}$ of $5 \mathrm{U} / \mu \mathrm{L}$ GoTaq DNA polymerase (Promega, Madison, Wisconsin). The PCR conditions were $94^{\circ} \mathrm{C}$ for $5 \mathrm{~min}$, followed by 40 cycles of $94^{\circ} \mathrm{C}$ for $30 \mathrm{~min}, 55^{\circ} \mathrm{C}$ for $1 \mathrm{~min}$, and $72^{\circ} \mathrm{C}$ for 1 min, and a final $10 \mathrm{~min}$ extension at $72^{\circ} \mathrm{C}$. The PCRamplified DNA fragments were digested with the restriction enzyme $\mathrm{NcoI}$ and the resulting $\sim 2.8 \mathrm{~kb}$ DNA fragment was inserted into the same restriction site of the plasmid pCAMBIA1380 (Cambia, Canberra, Australia). Positive recombinant plasmids that contained an approximately 2.8-kb full-length TYLCV clone were fully sequenced using an ABI 3730XL by Macrogen (Seoul, Korea). Positive clones were named pTYLCV- [JU] and one positive clone was used in subsequent work.

\section{Construction of TYLCV infectious clone}

An infectious TYLCV clone was constructed using a 1.8mer genome-length copy of TYLCV obtained from pTYLCV- [JU]. For this purpose, a $2.35 \mathrm{~kb} E c o R I / N c o I$ fragment of pTYLCV- [JU] was first cloned into the pCAMBIA1380 binary plasmid, which had been digested with EcoRI and NcoI to create pBTY [JU]P. Then, a $2.8 \mathrm{~kb}$ NcoI fragment of pTYLCV- [JU], the full-length TYLCV clone, was ligated into an NcoI-linearized pBTY [JU]P yielding pBTY [JU], a binary plasmid containing a 1.8mer of TYLCV- [JU].

\section{In vitro culture of plants}

Seeds of the TYLCV- susceptible S. lycopersicum line "NS16" were obtained from an advanced breeding program developed at the Jordanian National Seed Company. The NS16 tomato line originates from a cross between S. lycopersicum cv. Guardian (developed by the Enza-Zaden Seed Company), a highly TYLCV-susceptible tomato and S. lycopersicum cv. Elegro (developed by the Asgrow Seed Company), a TYLCV-resistant tomato (N. Abu Al Roz, personal communication). NS16 is a determinate tomato plant that yields dark red fruits of 220-250 g. Seeds of S. lycopersicum cv. Moneymaker were obtained from Gourmet Seed International Seed Company, USA. The seeds of $S$. habrochaites accession LA 1777 were kindly provided by C.M. Rick, TGRC, Davis, USA.

Seeds from plants of NS16, Moneymaker and LA 1777 were surface sterilized with $70 \%$ ethanol for one minute followed by soaking for 15 minutes in 3.5\% sodium hypochlorite plus $0.1 \%$ Tween-20. Seeds were rinsed 6 times with sterile water and then placed in a plastic vessel containing MS medium consisting of MS salt [20], $50 \mathrm{mg} /$ 1 myo-insitol, $2 \mathrm{mg} / \mathrm{l}$ thiamine $\mathrm{HC} 1,0.5 \mathrm{mg} / \mathrm{l}$ pyridoxine $\mathrm{HCl}, 0.5 \mathrm{mg} / \mathrm{l}$ nicotinic acid, $30 \mathrm{~g} / \mathrm{l}$ sucrose and $7 \mathrm{~g} / \mathrm{l}$ agar, with $\mathrm{pH}$ value adjusted to 5.8 before autoclaving. Seeds were germinated in a growth room $\left(24^{\circ} \mathrm{C}\right.$ under cool white fluorescent lights, $50-100 \mu \mathrm{Em}^{-2} \mathrm{sec}^{-1}$, with a photoperiod of 16 hours light/8 hours darkness). After 21 days, the tomato plantlets were used for the inoculation experiments. 


\section{Inoculation methods}

Competent cells of Agrobacterium tumefaciens strain GV3101 [21] were transformed by electroporation with either pCAMBIA1380 (negative control) or pBTY [JU]. Bacteria were grown for 24 hours at $28^{\circ} \mathrm{C}$ in Luria-Bertani (LB) media supplemented with appropriate antibiotics. Bacterial cells were harvested by centrifugation and resuspended to a final $\mathrm{OD}_{600}$ of 0.25 in liquid $\mathrm{MS}$ medium (without agar) supplemented with $100 \mu \mathrm{M}$ acetosyringone. Into a sterile Petri dish, $10 \mathrm{ml}$ of the bacterial suspension were poured. Microshoots (around $2.0 \mathrm{~cm}$ in length) were excised from 21 days old tomato plantlets and their basal parts were dipped for 30 seconds in the agrobacterial suspension. The inoculated microshoots (20 microshoot/inoculation test) were transferred into solid MS medium supplemented with $100 \mu \mathrm{M}$ acetosyringone and co-cultivated with the bacteria for 48 hours. After 48 hours of co-cultivation, microshoots were washed three times in sterile distilled water containing filter-sterilized cefotaxim $(500 \mathrm{mg} / \mathrm{l})$ and then transferred to glass tubes containing $15 \mathrm{ml}$ of solid MS medium supplemented with $500 \mathrm{mg} / \mathrm{l}$ cefotaxim, an antibiotic that kills bacterial cells. The inoculated microshoots were monitored for development of TYLCD symptoms for 8 weeks post-inoculation.

The effect of inoculum density on the TYLCV-infection efficiency was investigated using three different $\mathrm{OD}_{600}$ levels. For this purpose, agrobacterium cells were harvested and diluted to a final $\mathrm{OD}_{600}$ of $0.125,0.25$ or 0.5 in liquid MS medium supplemented with $100 \mu \mathrm{M}$ acetosyringone and the bacteria were then co-cultivated with NS16 tomato microshoots and monitored for development of TYLCD symptoms.

The effect of the dipping method on TYLCV-infection efficiency was also tested. For this purpose, either the basal part of a NS16 tomato microshoot was dipped for 30 seconds or the entire microshoot was soaked for 15 minutes in the agrobacterium solution $\left(\mathrm{OD}_{600}\right.$ of 0.25$)$ and then washed three times in sterile distilled water containing filter-sterilized cefotaxim $(500 \mathrm{mg} / \mathrm{l})$. The explants were then co-cultivated and monitored for the development of TYLCD symptoms as described above.

To inoculate greenhouse grown tomato plants with TYLCV, a leaf agroinfiltration method was used. For this purpose, the bacterial suspension was prepared as described above and was then infiltrated into the lower side of leaves of 2-weeks old plants using a $1 \mathrm{ml}$ needleless syringe. Inoculated plants were observed for the development of TYLCD symptoms for eight weeks postinoculation.

\section{TYLCV detection in inoculated plants}

To confirm the presence of TYLCV DNA in tissue-culture infected plants, PCR was performed using specific
TYLCV primers. DNA extracts from the in vitro-inoculated plants were isolated as described by Doyle and Doyle [18]. The DNA extracts were used as template for PCR amplification (as described above) of a $450 \mathrm{bp}$ long DNA fragment from the $C 1$ gene using the primers TYMF (5'-AAGCGCTTCCAAATAAATTG-3') and TYMR (5'-TACTAATTCTTTAATGATTC-3'). The PCR products were subjected to electrophoresis in a $1 \%$ agarose gel.

To verify presence of the full-length circular singlestranded genome of TYLCV in inoculated plants, rolling circle amplification (RCA) [22] using bacteriophage Phi29 DNA polymerase (New England BioLabs, MA, USA) was carried out as follows: $1 \mu \mathrm{g}$ of extracted total DNA was added to $5 \mu \mathrm{l}$ of dNTPs $(100 \mu \mathrm{M})$ and $5 \mu \mathrm{l}$ random hexamers $(2 \mathrm{pmol} / \mu \mathrm{l})$. The mixture was heated to $95^{\circ} \mathrm{C}$ for 5 minutes, chilled on ice, and combined with $5 \mu \mathrm{l}$ of reaction buffer plus 5 units of the Phi29 DNA polymerase. Water was added to a final volume of $50 \mu \mathrm{l}$. The reaction mixture was incubated for $18 \mathrm{~h}$ at $30^{\circ} \mathrm{C}$, followed by inactivation of the enzyme at $65^{\circ} \mathrm{C}$ for 10 minutes. The amplified DNA, containing tandem repeats of the TYLCV genome, was separated in a $1 \%$ agarose gel. In addition, the amplified DNA was digested with NcoI in order to detect a $\sim 2.8 \mathrm{~kb}$ band representing a linearized TYLCV genome in the inoculated plants.

\section{Results}

\section{Establishment of the TYLCV in vitro-inoculation method}

The complete genome of TYLCV was isolated from a tomato plant showing TYLCD symptoms using the overlapping primer method. The positive pTYLCV- [JU] clones were analyzed using several restriction enzymes and positive clones were completely sequenced. The isolate was found to show high sequence identity (99.4\%) with the TYLCV-Mld isolate [23]. A 1.8-mer DNA copy from the isolated TYLCV genome was cloned into pCAMBIA1380 to produce the infectious clone pBTY [JU]. The infectious clone was tested successfully in greenhouse-grown plants of the TYLCV-susceptible tomato line "NS16" using the leaf agroinfiltration method (data not shown). Four weeks after leaf agroinfiltration with pBTY [JU], typical symptoms of TYLCD were observed in $13 / 15$ of the inoculated plants, while tomato plants agroinfiltrated with pCAMBIA1380 remained symptomless.

To establish the TYLCV in vitro-inoculation method, basal parts of three weeks old microshoots obtained from in vitro-grown TYLCV-susceptible NS16 tomato plantlets were dipped for 30 seconds in solutions containing agrobacterium transformed with either the infectious clone pBTY [JU] or empty binary plasmid. The inoculated in vitro microshoots were monitored for development of TYLCV symptoms for 8 weeks post-inoculation. 
Table 1: Agroinoculation of in vitro-cultured NS16 and Moneymaker tomato plants with the infectious TYLCV clone pBTY [JU] and the negative control pCAMBIA1380.

\begin{tabular}{llcccc}
\hline Construct & Genotype & \multicolumn{2}{c}{ Experimenta (\% infected plantsb) } & & \\
\cline { 3 - 6 } & & I & II & Average \\
\hline PCAMBIA1380 & NS16 & & & & \\
& Moneymaker & $0[0 / 20]$ & $0[0 / 20]$ & $0[0 / 20]$ & $0[0 / 60]$ \\
& & & $0[0 / 20]$ & & $0[0 / 60]$ \\
PBTY [JU] & NS16 & $85[17 / 20]$ & $80[16 / 20]$ & $90[18 / 20]$ & $85[51 / 60]$ \\
& Moneymaker & $95[19 / 20]$ & $100[20 / 20]$ & $95[19 / 20]$ & $96.7[58 / 60]$ \\
\hline
\end{tabular}

a In each experiment, 20 plants were inoculated.

b Data were recorded 8 weeks post-inoculation. Infected plants percentages were determined from the numbers in brackets.

Table 1 summarizes the results obtained from three independent experiments. Over $85 \%$ of the in vitro-inoculated tomato microshoots with pBTY [JU] had typical TYLCD symptoms, while all of the tomato microshoots inoculated with the pCAMBIA1380 plasmid remained symptomless and continued their growth normally. However, $15 \%$ of the in vitro-inoculated tomato microshoots were considered healthy with no obvious TYLCD symptoms and they continued to grow normally (Table 1). The results obtained showed the feasibility to inoculate efficiently in vitro tomato plants with TYLCV and typical symptoms of TYLCD with leaf curling and yellowing were observed.

For symptom development, NS16 tomato microshoots inoculated with the empty plasmid did not show any TYLCD symptoms and continued to grow normally (Figure 1A). The development of TYLCD symptoms in some plants was first observed 2 weeks post inoculation (Figure 1B). After 4 weeks, NS16 tomato plants in vitro-inoculated with $\mathrm{pBTY}[\mathrm{JU}]$ continued to display symptoms of stunting, upward leaf curling and yellowing (Figure $1 \mathrm{C}$ ). After 8 weeks, the TYLCV-inoculated plants showed pronounced TYLCD symptoms when compared with plants inoculated with the pCAMBIA1380 plasmid (Figure 1D). The presence of TYLCV in the in vitro-inoculated plants showing TYLCD symptoms was verified by PCR and RCA (Figure 2). The TYLCD symptoms in in vitro-inoculated plants were similar to in vitro-cultured plants derived from nodal explants of tomato plants inoculated with TYLCV in the greenhouse (data not shown). The in vitro-inoculated plants with TYLCD symptoms were kept in culture for 6 months indicating the feasibility to maintain TYLCV in vitro using this method (Figure 1E). In addition, it was possible to transfer the in vitro-inoculated plants to greenhouse conditions after two weeks of acclimatization.

Furthermore, the in vitro-inoculation method was tested successfully and similar results were obtained with other TYLCV-susceptible tomato cultivars, such as Moneymaker (Table 1). The in vitro-inoculated Moneymaker plants showed similar TYLCD symptoms when compared to the in vitro-inoculated line NS16 microshoots after eight weeks of inoculation (data not shown). However, the in vitro-inoculated Moneymaker and "line NS16" plants showed variation in infection percentages (Table 1). In general, the in vitro-inoculated Moneymaker plants had higher infection percentage values when compared to the in vitro-inoculated line NS16 plants.

The effect of inoculum density on the TYLCV-infection efficiency was tested using three different $\mathrm{OD}_{600}$ $(0.125,0.25$ or 0.5$)$. The results from two independent experiments using NS16 tomato microshoots showed that bacterial densities of both 0.25 and 0.5 produced a high percentage of TYLCV infected plants (over $70 \%$ of inoculated plants) compared to a density of 0.125 (50\% of inoculated plants) (Additional file 1). In some instances, plant death was observed (30\% of inoculated plants) when an $\mathrm{OD}_{600}$ of 0.5 was used due to agrobacteria overgrowth (Additional file 1). These results indicate that an $\mathrm{OD}_{600}$ of 0.25 is considered optimum for inducing TYLCD symptoms in the in vitro-inoculation method.

In the treatment where the whole plant was completely soaked in the agrobacterium solution, the percentage of TYLCV infectivity was very low compared to the treatment with 30 seconds of basal dipping (Additional file 2). The complete soaking of NS16 microshoots resulted in the browning and necrosis of all inoculated microshoots eight weeks post-inoculation (data not shown). In fact, $62.5 \%$ of plants soaked in the agrobacterium solution died four weeks post-inoculation (Figure 3A and Additional file 2). In addition, the surviving inoculated soaked plants (37.5\% of inoculated plants) showed terminal bud death and the newly developed shoots from the axillary buds were infected and showed typical TYLCD symptoms (Figure 3B and Additional file 2). In some instances, the soaked plants showed overgrowth of agrobacteria four 

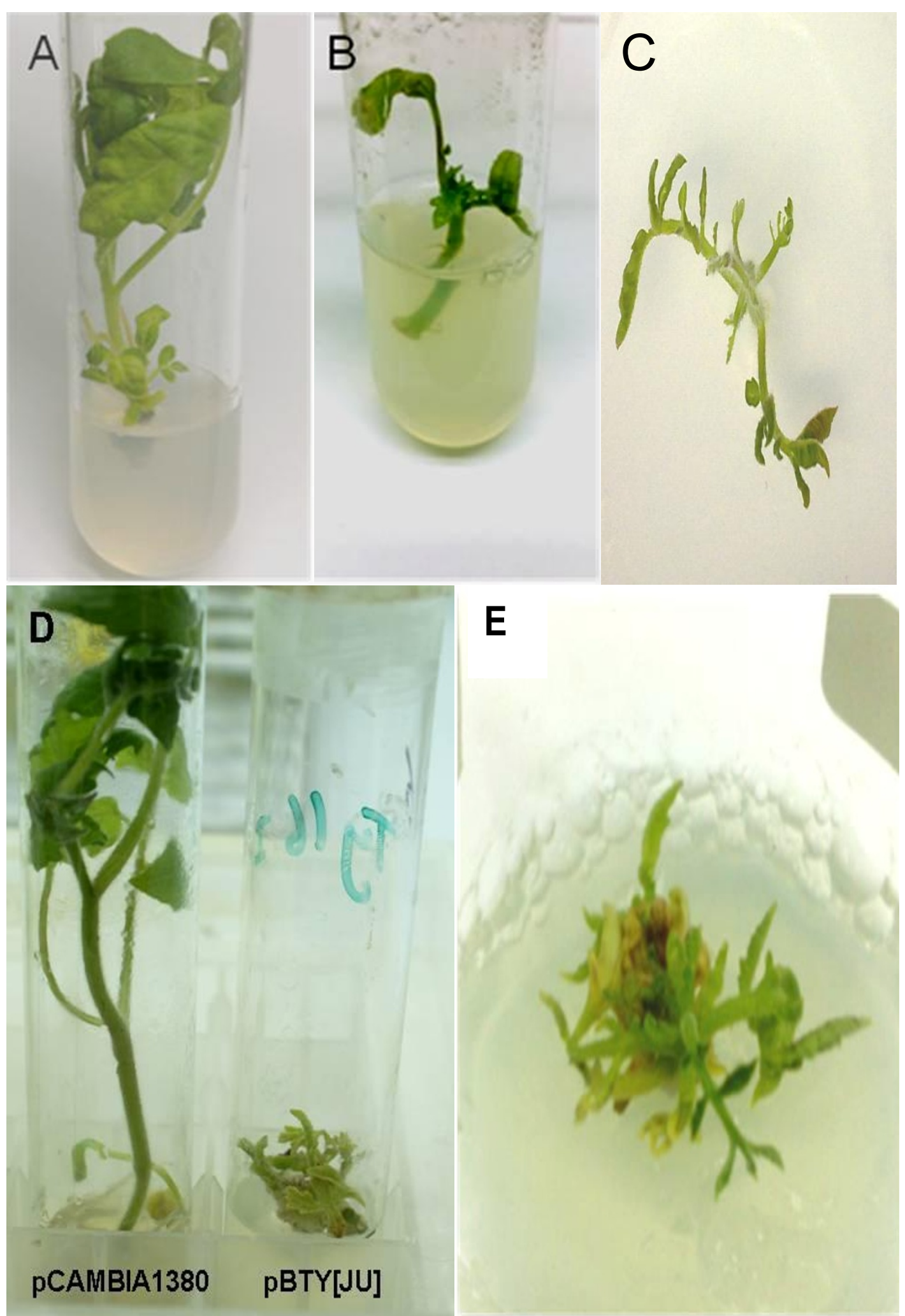

Figure 1 Symptoms on in vitro-cultured NS16 tomato plants inoculated with the infectious TYLCV clone pBTY [JU]. (A) Tomato plant 4 weeks after inoculation with pCAMBIA1380 (negative control). (B) Tomato plant 2 weeks after inoculation with pBTY [JU]. (C) Tomato plant 4 weeks after inoculation with pBTY [JU]. (D) Tomato plant 8 weeks after inoculation with pCAMBIA1380 (left) or pBTY [JU] (right). (E) Tomato plant 6 months after inoculation with $\mathrm{pBTY}[\mathrm{JU}]$. 


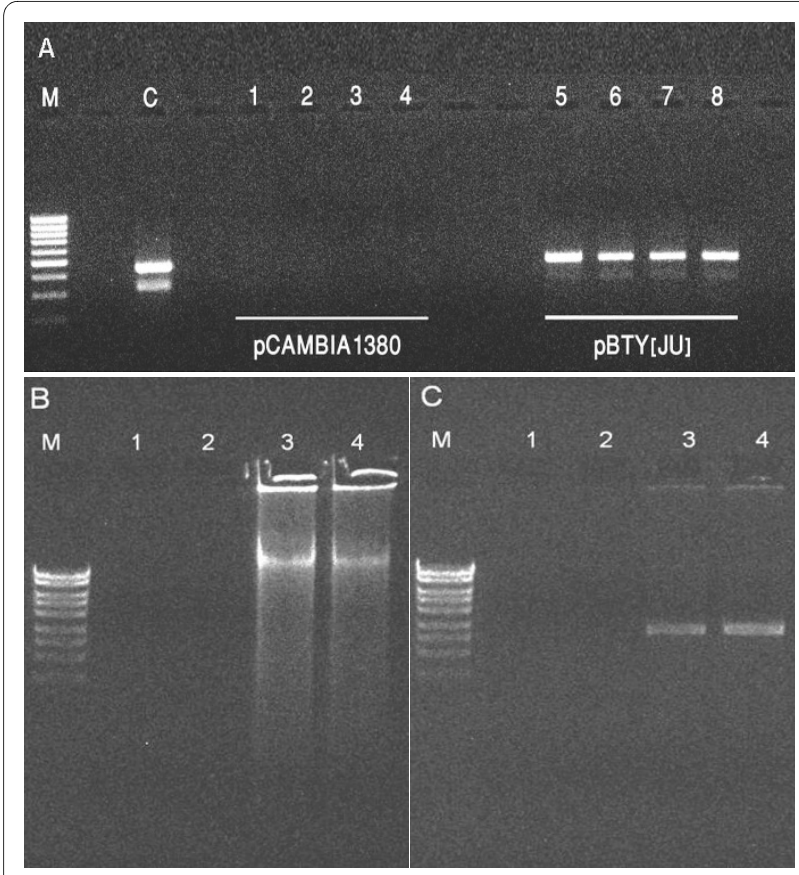

Figure 2 Detection of TYLCV DNA in tissue-cultured NS16 tomato plants after inoculation with the infectious TYLCV clone $\mathrm{pBTY}$ [JU]. (A) Agarose gel showing PCR products (450 bp) amplified with the primer pair TYMF/TYMR from DNA extracts of plants inoculated in vitro with TYLCV. Lanes 1-4: DNA extracts from plants inoculated with pCAMBIA1380 (negative control); Lanes 5-8: DNA extracts from plants inoculated with pBTY [JU]. C: pBTY [JU] plasmid (positive control). M: Low range DNA marker (Fermentas). (B) Agarose gel showing amplification products after rolling circle amplification (RCA) with DNA of plants inoculated with TYLCV in vitro. Lanes 1-2: DNA extracts from plants inoculated with pCAMBIA1380 (negative control); Lanes 3-4: DNA extracts from plants inoculated with pBTY [JU]. M: High range DNA marker (Fermentas). (C) Agarose gel showing TYLCV DNA after digestion of the RCA products with Ncol. Lanes 1-2: DNA extracts from plants inoculated with pCAMBIA1380 (negative control); Lanes 3-4: DNA extracts from plants inoculated with PBTY [JU]. M: High range DNA marker (Fermentas).

weeks post-inoculation, while with basal dipping no bac-

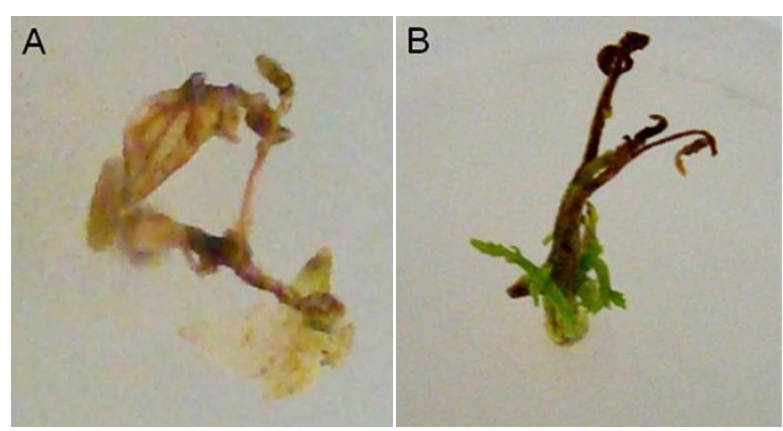

Figure 3 Inoculation of in vitro-cultured NS16 tomato plants with the infectious TYLCV clone pBTY [JU] using the soaking method. (A) Dead tomato plant 4 weeks after inoculation. (B) Growth of axillary bud in tomato plant 4 weeks after inoculation. terial overgrowth was observed (data not shown). These results indicate that dipping the basal part of the explant is sufficient and suitable for the purpose of in vitro-inoculation of tomato plants with TYLCV.

\section{Testing the in vitro inoculation method with TYLCV- resistance plants}

To test the in vitro-inoculation method with TYLCVresistant wild tomato plants, in vitro cultures of S. habrochaites accession LA 1777 were established and microshoots were inoculated and monitored for TYLCD symptoms as described above. S. habrochaites LA 1777 is known for its high levels of resistance against the whitefly insect, the transmission of the virus by the insect and its tolerance to TYLCV and it is commonly used in breeding programs to produce tomato plants with improved resistance against TYLCV [24]. In contrast to the results obtained with the in vitro-inoculation of susceptible tomato plants, all LA 1777 microshoots (results of two experiments with 20 microshoots per experiment) did not show any TYLCD symptoms even 4 weeks after inoculation and they continued to grow normally and similarly to microshoots inoculated with the empty binary plasmid (Figure 4). Although LA 1777 plants were symptomless, PCR and RCA analysis showed the presence of TYLCV DNA in inoculated plants verifying the presence of a resistance mechanism [23] against the virus preventing TYLCD symptoms development (Figure 5). These results indicate the possibility to identify the mechanism of resistance against TYLCV in wild tomato genotypes using in vitro cultures.

\section{Discussion}

In this study, an efficient in vitro-inoculation method for TYLCV was developed that is suitable for screening different tomato genotypes for their responses to TYLCV. The presented in vitro-inoculation method proved to be efficient and reliable. Such method is needed to overcome pitfalls reported for other TYLCV inoculation methods $[3,8]$. For instance, previous reports discourage the use of whitefly-inoculation methods due to difficulties related to controlling infection pressure, the escape of some plants from the infection and the influence of environmental conditions on TYLCD symptom development $[9,10]$. Furthermore, the in vitro-inoculation method can be adapted to inoculate plant species considered to be "non-host" by the whiteflies $[8,10]$. Inoculation methods depending on stem or leaf agroinfiltration under greenhouse conditions require extra measurements to avoid external infection and are inefficient in some plants $[11,12,14]$. Discrepancy in results of TYLCV inoculation using particle bombardment has been shown previously. For instance, Morilla et al. [14] successfully inoculated tomato plants with DNA of TYLCV- [Alm] from Alme- 


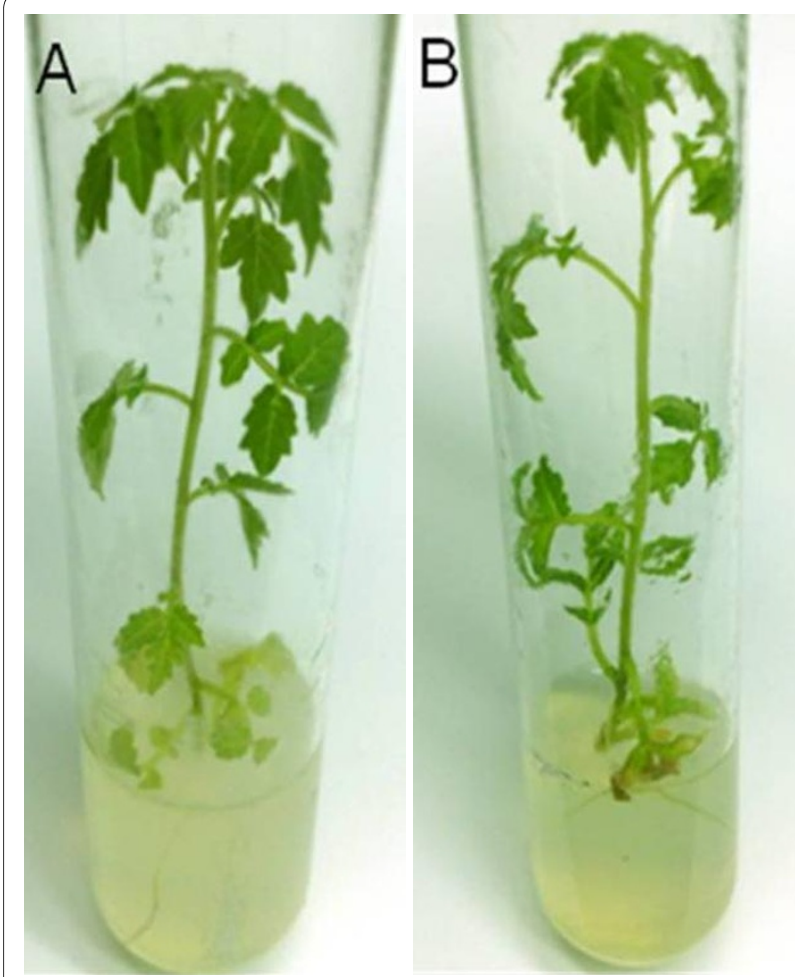

Figure 4 Lack of symptoms for in vitro-cultured plants of Solanum habrochaites accession LA 1777 inoculated with the infectious TYLCV clone pBTY [JU]. (A) Plant of S. habrochaites accession LA 1777 4 weeks after inoculation with pCAMBIA1380 (negative control). (B) Plant of S. habrochaites accession LA 17774 weeks after inoculation with $\mathrm{PBTY}[\mathrm{JU}]$.

ria, while Ramos et al. [15] were unsuccessful even though they used a similar approach with TYLCV- [CU] from Cuba and TYLCSV. Furthermore, the efficiency of TYLCV infectivity using particle bombardment differed with the plant species [13]. Testing the in vitro-inoculation system on two different genotypes revealed the presence of variation in infection percentages (Table 1). Such variation in infection rates might indicate variability in responses to TYLCV infection between the two genotypes.

The described in vitro system is suitable for in vitro storage of TYLCV-infected plant material (Figure 1E). With this respect, Pelah et al. [25] reported the establishment of callus cultures from TYLCV-infected tomato plants that were suitable for in vitro storage of TYLCVinfected callus up to 8 months. Similar tissue culture approaches were developed for the purpose of Tobacco mosaic virus (TMV) propagation in hairy root cultures of Nicotiana benthamiana where the hairy root cultures were directly inoculated by the addition of the virus to the culture medium [26]. Therefore, the described in vitro-inoculation method can be used for prolonged stor-
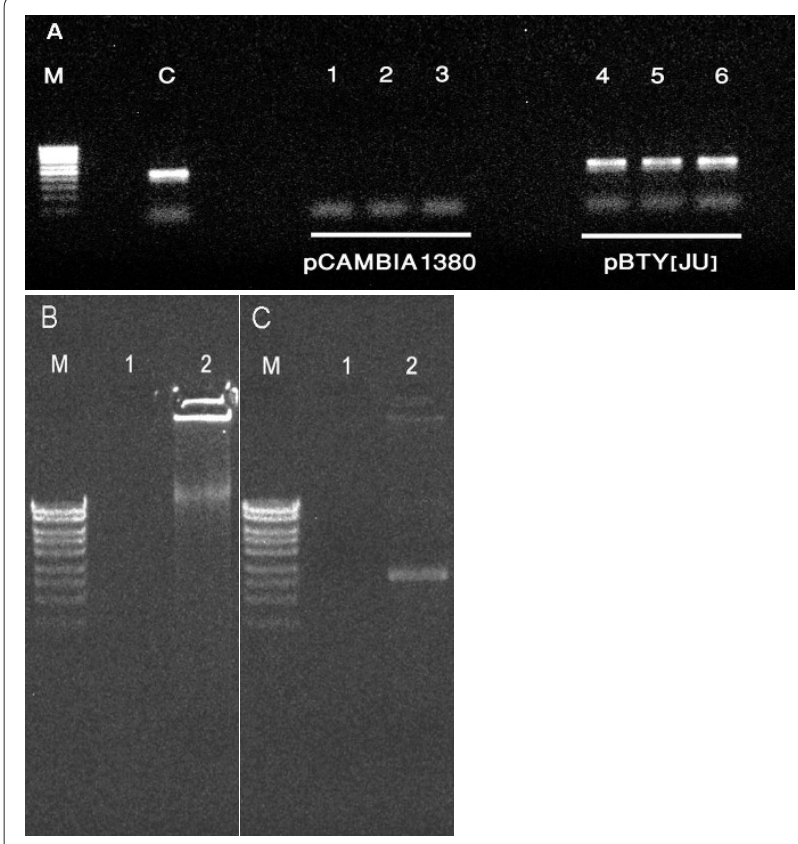

Figure 5 Detection of TYLCV DNA in tissue culture plants of Solanum habrochaites accession LA 1777 after inoculation with the infectious TYLCV clone pBTY [JU]. (A) Agarose gel showing PCR products (450 bp) amplified with the primer pair TYMF/TYMR from DNA extracts of plants inoculated in vitro with TYLCV. Lanes 1-3: DNA extracts from plants inoculated with pCAMBIA1380 (negative control); Lanes 4-6: DNA extracts from plants inoculated with pBTY [JU]. C: pBTY [JU] plasmid (positive control). M: Low range DNA marker (Fermentas). (B) Agarose gel showing amplification products after rolling circle amplification (RCA) with DNA of plants inoculated with TYLCV in vitro. Lane 1: DNA extract from plant inoculated with pCAMBIA1380 (negative control); Lane 2: DNA extract from plant inoculated with pBTY [JU]. M: High range DNA marker (Fermentas). (C) Agarose gel showing TYLCV DNA after digestion of the RCA products with Ncol. Lane 1: DNA extract from plant inoculated with pCAMBIA1380 (negative control); Lanes 2: DNA extracts from plants inoculated with pBTY [JU]. M: High range DNA marker (Fermentas).

age of infected material and can be used in exchanging infected plant materials between locations.

Two previous reports describe systems suitable for the inoculation of in vitro-grown plants with viruses. Mazier et al. [16] have described a simple and efficient system for in vitro inoculation of lettuce plants with Lettuce mosaic virus (LMV). The principle of their method relies on the mechanical inoculation of in vitro-grown lettuce plantlets using latex fingers dipped in sap extract from greenhouse-grown infected plants. In another study, nodal cuttings from in vitro-cultured potato, tomato and tobacco plants have been infected in vitro with Potato virus $Y$ (PVY) using mechanical and grafting inoculation [17]. However, the PVY symptoms on the in vitro-infected plants were not as obvious as those observed on greenhouse-grown infected plants. Both systems are based on mechanical inoculation and this is not applicable for 
TYLCV, which cannot be transmitted by mechanical inoculation. The in vitro-inoculation method described here needs agrobacterium to deliver the infectious TYLCV clone into in vitro-grown tomato plants. Similar to our approach, agroinoculation of aseptically grown $N$. benthamiana plants for the purpose of virus-induced gene silencing has been successful and targeted genes were silenced one week post-inoculation [12].

Similar to the method developed by Russo \& Salck [17], the reported method is suitable for initial screening of virus resistance in transgenic plants. It can reduce the time needed to evaluate the performance of transgenic plants and it is suitable for testing such plants under controlled environment and thus meeting the regulations for testing transgenic plants. In addition, the current described in vitro-inoculation method can be used to test the responses of different plant species to inoculation with TYLCV strains not prevalent in certain geographical areas. This would prevent the spread of viral strains to new areas, which is a risk issue when using inoculations in greenhouses or fields. The described method can facilitate studying the biological interactions between different tomato genotypes and different begomoviruses. In addition, the developed in vitro-inoculation method can be adapted to infect tomato plants simultaneously with different viral strains or species, which is difficult to perform using natural or whitefly-inoculation methods. Furthermore, the method is suitable for testing the specificity of interaction between different tomato genotypes and TYLCV strains avoiding cross contamination with other viruses and pathogens that are common using inoculations in greenhouses or fields. Additionally, the described in vitro-inoculation method is aseptic and it will eliminate the presence of other pathogens that might cause overlapping symptoms with the TYLCD in vivo.

The TYLCD symptoms were obvious on the in vitroinoculated plants, although sometimes overlap with the tissue culture-induced phenotype was observed (Figure 1). However, the TYLCD symptoms of plants inoculated in vitro were similar to in vitro-cultured plants derived from nodal explants of tomato plants inoculated with TYLCV in the greenhouse (data not shown). The TYLCV symptoms were absent when the in vitro-inoculation method was tested on wild tomato plants known for their resistance against TYLCV. Therefore, it is necessary to detect the virus using molecular tools such as PCR, Southern blot analysis or RCA.

The in vitro-inoculation method described here can be used to understand the mechanisms of resistance against TYLCV in wild tomato genotypes. Using this method with S. habrochaites LA 1777, a wild tomato showing resistance to both whitefly and TYLCV [24], the presence of a TYLCV resistance mechanism was unmasked (Figure 4). Using the in vitro-inoculation method, the TYLCV- inoculated LA 1777 microshoots were symptomless for TYLCD, but tested positive for TYLCV using PCR and RCA (Figure 5). LA 1777 plants grown under greenhouse conditions and subjected to inoculation with viruliferous whiteflies and PCR analysis revealed the presence of both immune (virus is not detectable in the plant) and tolerant (virus is detectable in the plant, but the TYLCD symptoms are absent) mechanisms against TYLCV [unpublished results], which is consistent with previous reports [24]. Several attempts to transmit TYLCV to LA 1777 through grafting with infected tomato plants or natural infection under greenhouse conditions failed [unpublished results]. The current method can overcome such limitations related to incompatibility between scion and stock or natural inoculation difficulties due to whitefly non-preference. According to Vidavsky \& Czosnek [24], the mechanisms of resistance in LA 1777 are expressed at the whitefly-plant interface (viral transmission) and internally in the plant (TYLCD symptoms development); therefore, by using natural inoculation methods, the resistance at the whitefly-plant interface will mask the resistance toward the virus inside the plant. Using the described in vitro-inoculation method, it was possible to overcome such limitation and it was feasible to uncover the natural resistance of LA 1777 to TYLCV. This is in general agreement with the results of Kheyr-Pour et al. [27], where in vivo agroinoculation was used to break the TYLCV resistance in LA 1777.

\section{Conclusions}

In this study, an efficient method suitable for in vitro inoculation of tomato plants with TYLCV was developed. The method was used efficiently to unmask the TYLCV resistant in wild tomato. The current method allows the storage and propagation of infected tomato plants under proper controlled conditions. The described in vitro method will be recommended for initial screens of transgenic plants with improved resistance against TYLCV.

\section{Additional material}

\footnotetext{
Additional file 1 Effect of inoculum density on in vitro-cultured NS16 tomato plants inoculated with the infectious TYLCV clone PBTY [JU]. A table showing the responses of tomato microshoots following the inoculation with three different inoculum densities of agrobacteria harboring the infectious TYLCV clone PBTY[JU].

Additional file 2 Effect of inoculation method on in vitro-cultured NS16 tomato plants inoculated with the infectious TYLCV clone. A table showing the responses of tomato microshoots to the inoculation with the infectious TYLCV clone PBTY [JU] using two different methods.
}

Competing interests

The authors declare that they have no competing interests.

\section{Authors' contributions}

AMA conceived the research, performed most of the experiments, and wrote the manuscript; HSD collected the samples and monitored the TYLCD symptoms development; SM helped in the molecular work; HA and AQ helped in 
the tissue culture work; AK developed the conceptual aspects of the work and edited the manuscript; All authors read and approved the final manuscript.

\section{Acknowledgements}

The authors wish to thank the Jordanian National Seeds Production company for kindly providing seeds of tomato line "NS16". We are grateful to C.M. Rick, TGRC, Davis, USA for the seeds of Solanum habrochaites accession LA 1777. This work was supported in part by a grant from the Hamdi Mango Center for Scientific Research, University of Jordan and by the Swedish Research Links Programme (Swedish International Development Cooperation Agency and Swedish Research Council).

\section{Author Details}

1Department of Horticulture and Crop Science, Faculty of Agriculture, University of Jordan, Amman 11942, Jordan, 2Agricultural Biotechnology Laboratories, Hamdi Mango Center for Scientific Research, University of Jordan, Amman 11942, Jordan and ${ }^{3}$ Department of Plant Biology and Forest Genetics, Uppsala BioCenter SLU, Box 7080, SE-750 07 Uppsala, Sweden

Received: 5 March 2010 Accepted: 29 April 2010

Published: 29 April 2010

\section{References}

1. Cohen S, Harpaz I: Periodic rather than continual acquisition of a new tomato virus by its vector, the tobacco whitefly (Bemisia tabaci Gennadius). Entomol Exp Appl 1964, 7:155-166.

2. Czosnek H, Ber R, Antignus Y, Cohen S, Navot N, Zamir D: Isolation of the Tomato yellow leaf curl virus - a geminivirus. Phytopathology 1988, 78:508-512.

3. Lapidot $M$, Friedmann M: Breeding for resistance to whiteflytransmitted geminiviruses. Ann Appl Biol 2002, 140:109-127.

4. Vidavski FS: Exploitation of resistance genes found in wild tomato species to produce resistant cultivars; Pile up of resistant genes. In Tomato Yellow Leaf Curl Virus Disease Edited by: Czosnek H. The Netherlands: Springer; 2007:363-372

5. Ji Y, Scott JW, Hanson P, Graham E, Maxwell DP: Sources of resistance, inheritance, and location of genetic loci conferring resistance to members of the tomato-infecting begomoviruses. In Tomato Yellow Leaf Curl Virus Disease Edited by: Czosnek H. The Netherlands: Springer; 2007:343-362.

6. Lapidot M, Polston JE: Resistance to Tomato yellow leaf curl virus in Tomato. In Tomato Yellow Leaf Curl Virus Disease Edited by: Czosnek H. The Netherlands: Springer; 2007:503-520.

7. Zamir D, Ekstein-Michelson I, Zakay Y, Navot N, Zeidan M, Sarfatti M, Eshed Y, Harel E, Pleban T, van-Oss H, Kedar N, Rabinowitch HD, Czosnek H: Mapping and introgression of a tomato yellow leaf curl virus tolerance gene, $T Y$-1. Theor 1994, 88:141-146.

8. Lapidot M: Screening for TYLCV-resistant plants using whiteflymediated inoculation. In Tomato Yellow Leaf Curl Virus Disease Edited by: Czosnek H. The Netherlands: Springer; 2007:329-342.

9. Vidavsky F, Leviatov S, Milo J, Rabinowitch HD, Kedar N, Czosnek H: Response of tolerant breeding lines of tomato, Lycopersicon esculentum, originating from three different sources ( $L$. peruvianum, $L$. pimpinellifolium and $L$. chilense) to early controlled inoculation by tomato yellow leaf curl virus (TYLCV). Plant Breeding 1998, 117:165-169.

10. Pico B, Diez MJ, Nuez F: Evaluation of whitefly-mediated inoculation techniques to screen Lycopersicon esculentum and wild relatives for resistance to tomato yellow leaf curl virus. Euphytica 1998, 101:259-271.

11. Liu YL, Schiff M, Dinesh-Kumar SP: Virus-induced gene silencing in tomato. Plant 2002, 31:777-786.

12. Ryu CM, Anand A, Kang L, Mysore KS: Agrodrench40: a novel and effective agroinoculation method for virus-induced gene silencing in roots and diverse Solanaceous species. Solanaceous 2004:322-331.

13. Lapidot M, Weil G, Cohen L, Segev L, Gaba V: Biolistic inoculation of plants with Tomato yellow leaf curl virus DNA. J Virol Methods 2007 144:143-148.

14. Morilla G, Janssen D, Garcia-Andres S, Moriones E, Cuadrado IM, Bejarano ER: Pepper (Capsicum annuum) is a dead-end host for tomato yellow leaf curl virus. Phytopathology 2005, 95:1089-1097.

15. Ramos PL, Guevara-Gonzalez RG, Peral R, Ascencio-Ibanez JT, Polston JE, Arguello-Astorga GR, Vega-Arreguin JC, Rivera-Bustamante RF: Tomato mottle Taino virus pseudorecombines with PYMV but not with ToMoV implications for the delimitation of cis - and trans -acting replication specificity determinants. Arch 2003, 148:1697-1712.

16. Mazier M, German-Retana S, Flamain F, Dubois V, Botton E, Sarnette V, Le Gall O, Candresse T, Maisonneuve B: A simple and efficient method for testing Lettuce mosaic virus resistance in in vitro cultivated lettuce. $J$ Virol Methods 2004, 116:123-131.

17. Russo P, Slack SA: Tissue culture methods for the screening and analysis of putative virus-resistant transgenic potato plants. Phytopathology 1998, 88:437-441

18. Doyle JJ, Doyle JL: A rapid DNA isolation procedure from small quantities of fresh leaf tissue. Phytochem 1987, 19:11-15.

19. Patel V, Roja MR, Paplomatas EJ, Gilbertson RL: Cloning biologicallyactive geminivirus DNA using PCR and overlapping primers. Nucleic Acids Res 1993, 21:1325-1326.

20. Murashige T, Skoog F: A revised medium for rapid growth and bioassays with tobacco tissue culture. Physiol 1962, 15:473-497.

21. Koncz C, Schell J: The promoter of Ti -DNA gene 5 controls the tissuespecific expression of chimeric genes carried by a novel type of Agrobacterium binary vector. Mol Gen Genet 1986, 204:383-396.

22. Inoue-Nagata AK, Albuquerque LC, Rocha WB, Nagata T: A simple method for cloning the complete begomovirus genome using the bacteriophage phi29 DNA polymerase. J Virol Methods 2004, 116:209-211.

23. Antignus $Y$, Cohen S: Complete nucleotide-sequence of an infectious clone of a mild isolate of Tomato yellow leaf curl virus (TYLCV). Phytopathology 1994, 84:707-712.

24. Vidavsky F, Czosnek H: Tomato breeding lines resistant and tolerant to Tomato yellow leaf curl virus issued from Lycopersicon hirsutum. Phytopathology 1998, 88:910-914.

25. Pelah D, Altman A, Czosnek H: Tomato yellow leaf curl virus-DNA in callus-cultures derived from infected tomato leaves. Plant Cell Tissue Organ Cult 1994, 39:37-42.

26. Shih SM, Doran PM: In vitro propagation of plant virus using different forms of plant tissue culture and modes of culture operation. $J$ Biotechnol 2009, 143:198-206.

27. Kheyr-Pour A, Gronenborn B, Czosnek H: Agroinoculation of tomato yellow leaf curl virus (TYLCV) overcomes the virus resistance of wild Lycopersicon species. Plant 1994, 112:228-233.

doi: $10.1186 / 1743-422 X-7-84$

Cite this article as: Al Abdallat et al., An efficient in vitro-inoculation method for Tomato yellow leaf curl virus Virology Journal 2010, 7:84

\section{Submit your next manuscript to BioMed Centra and take full advantage of:}

- Convenient online submission

- Thorough peer review

- No space constraints or color figure charges

- Immediate publication on acceptance

- Inclusion in PubMed, CAS, Scopus and Google Scholar

- Research which is freely available for redistribution 